\title{
APORTES DE RUY MAURO MARINI AO DEBATE SOBRE O ESTADO NOS PAÍSES DEPENDENTES
}

\author{
Maíra Machado Bichir*
}

\begin{abstract}
No presente artigo, lançamos nosso olhar para uma temática de especial relevância para o contexto político atual latino-americano - o Estado. Ao revisitar os escritos de Ruy Mauro Marini, uma das principais referências da Teoria Marxista da Dependência, chamamos atenção para suas formulações em torno dos Estados latino-americanos, sobretudo no que se refere a seu caráter dependente, tema ainda pouco trabalhado nos estudos recentes de recuperação de sua obra. Nesse sentido, iniciamos nosso percurso tecendo algumas considerações sobre a concepção de Estado de Marini, salientando sua filiação à tradição teórica marxista, avançando, em seguida, para suas elaborações sobre as particularidades do Estado capitalista dependente latino-americano propriamente, centrando-nos, sobretudo, em dois temas que representam, em nossa perspectiva, dois importantes aportes de Marini à análise dos Estados latino-americanos: suas formulações em torno do subimperialismo e do Estado de contrainsurgência.
\end{abstract}

Palavras-chave: Estado. Dependência. América Latina. Política. Teoria marxista da dependência.

\section{INTRODUÇÃO}

A obra de Ruy Mauro Marini ocupa um lugar de destaque no movimento de recuperação da produção intelectual da Teoria Marxista da Dependência no Brasil. Desde a década de 2000, os conceitos de superexploração do trabalho e subimperialismo, formulados por Marini no final da década de 1960, vêm ganhando atualizações, críticas e revisões de diversos estudiosos e estudiosas, no campo do marxismo brasileiro. ${ }^{1}$ Embora tais conceitos

* Universidade Federal da Integração Latino-americana (UNILA). Instituto Latino-americano de Economia e Sociedade (ILAESP).

Av. Tancredo Neves, 6731, Bloco 6, Espaço 4, Sala 05. Foz do Iguaçu - Paraná - Brasil. mairabichir@gmail.com

${ }^{1}$ Aos escritos de Jaime Osorio $(2004,2009,2013)$ e Adrián Sotelo (2003, 2012), discípulos e estudiosos do pensamento de Ruy Mauro Marini de longa data, podemos elencar um movimento mais recente de debate sobre o conceito de superexploração do trabalho, que teve lugar no Brasil, consubstanciando-se em uma série de artigos, dentre os quais podemos citar: Amaral e Carcanholo (2008, 2009) Carcanholo (2013); Carcanholo e Côrrea (2016); Luce (2012, 2013a); Martins (2017). Alguns dos temas que têm sido discutidos dizem respeito à atualidade e validade do conceito de superexploração do trabalho, à revisão da formulação original de Marini, à extensão ou não do uso do conceito na análise dos países imperialistas. De maneira semelhante, o conceito de subimperialismo tem sido resgatado, nos últimos dez anos, para analisar a posição brasileira em relação aos países latino-americanos. São exemplos desses estudos: Luce (2013b); Fontes (2010); Bueno e Seabra (2012). adquiram centralidade nas principais obras de Marini, Dialética da Dependência e Subdesenvolvimento e Revolução, o conjunto de sua produção teórica é bastante amplo, abrangendo estudos dedicados à interpretação de realidades particulares, como a brasileira e a chilena, passando por temáticas como democracia, integração regional, universidade e movimento estudantil, processos revolucionários e contrarrevolucionários, bem como reflexões em torno das vanguardas políticas e do pensamento político e social - adotando a América Latina como ponto de partida e chegada para suas reflexões.

O tema que nos ocupa neste artigo, ${ }^{2} \mathrm{o}$ Estado, também foi objeto de análise por Marini, não tendo sido realizado, entretanto, até o momento, um estudo sistemático da produção de Marini em torno de tal questão. Considerando o momento político latino-americano, marcado por recentes crises e golpes políticos, entendemos que a questão do Estado, na América Latina, adquire fundamental relevância,

${ }^{2} \mathrm{O}$ presente artigo foi produzido a partir de minha tese de doutorado, intitulada A questão do Estado na Teoria marxista da dependência (Cf. Bichir, 2017). 
exigindo um olhar atento para suas particularidades. É nesse sentido que revisitamos aqui as contribuições presentes na obra de Ruy Mauro Marini, cujas reflexões lançam luz sobre as articulações entre Estado e dependência em nossa região.

Apresentaremos, inicialmente, um estudo sobre a concepção de Estado de Marini, avançando, em seguida, para suas elaborações em torno das especificidades do Estado capitalista dependente latino-americano, centrando-nos, sobretudo, em dois temas que representam, em nossa perspectiva, dois importantes aportes do autor à análise dos Estados latino-americanos: suas formulações em torno do subimperialismo e do Estado de contrainsurgência.

\section{A CONCEPÇÃO DE ESTADO DE MARINI}

Não há, na obra de Marini, algum escrito que reúna ou sistematize sua concepção sobre o Estado, fato que, embora dificulte, não impede que se reconstitua, a partir do agrupamento de elementos dispersos em diferentes momentos de sua produção, a visão do autor sobre tal objeto. Além de se encontrarem definições sobre o Estado nos artigos dedicados especificamente ao tema, constituem fontes para tal procedimento artigos que discutem temas como a transição ao socialismo, a universidade na América Latina, análises concretas do autor sobre processos políticos na América Latina, como nos casos chileno, cubano e nicaraguense, nos quais estão presentes referências às formulações marxistas clássicas, críticas a concepções de Estado de outros autores, como é o caso de Louis Althusser, - Celso Furtado, Lelio Bassio, bem como elaborações e interpretações próprias de Marini em torno do aparelho estatal.

Embora a problemática do Estado não tenha ocupado lugar central em suas obras, a confrontação entre seus escritos e os programas de dois de seus cursos, História Mundial Econômica I e II, oferecidos na Universidad
Nacional Autónoma de México (UNAM), em $1980,{ }^{3}$ por outro lado, permitem afirmar que Marini estava familiarizado não apenas com a discussão do Estado nos autores marxistas clássicos - Karl Marx, Friedrich Engels, Vladimir I. Lênin, Antonio Gramsci, Karl Kautsky e Rosa Luxemburgo -, como também com os debates que lhe eram contemporâneos, nas figuras de Louis Althusser, Nicos Poulantzas e Ralph Miliband, que, a partir de suas originais contribuições, trouxeram novo fôlego ao estudo do Estado sob a ótica do marxismo. Sua filiação teórica a essa corrente do pensamento, nesse sentido, além de se mostrar evidente em sua análise sobre o processo de acumulação e reprodução capitalista, também se explicita em seu entendimento acerca do aparelho estatal, na medida em que destaca como elemento central sua indissociabilidade com a dominação de classe. Tal nexo é sublinhado em sua resenha sobre o livro Dialéctica del Desarrollo, de Celso Furtado, quando Marini chama a atenção para o equívoco cometido pelo autor, em sua interpretação da conhecida passagem de Engels, em A origem da família, da propriedade privada e do Estado, segundo a qual "[...] há períodos em que as lutas de classes se equilibram de tal modo, que o Poder do Estado, como mediador aparente, adquire certa independência momentânea em face das classes" (Engels, [1884] 1977, p. 194). Ao atribuir ao Estado a capacidade de desempenhar um papel autônomo nos conflitos de classe, Furtado teria desconsiderado que "[...] el ejercicio directo e indirecto [grifo do autor] del poder por la clase dominante son grados de su dominación efectiva sobre el aparato del Estado, el cual, en ninguna hipótesis, se desvincula, en el pensamiento marxista, de la dominación de clase" (Marini, 1965, p. 214, grifo nosso).

Identificamos três passagens na obra de Marini, orientadas propriamente para a definição do que é o Estado, as quais, por sua vez,

${ }^{3}$ Os programas das disciplinas referidas estão disponíveis no sítio eletrônico "Ruy Mauro Marini - Escritos", na seguinte página: <http://www.marini-escritos.unam. mx/007_cursos_marini.html $>$. 
abrigam duas visões distintas. Na primeira delas, presente no artigo La pequena burguesía y el problema del poder ${ }^{4}$ (1973), Marini salienta a relação existente entre Estado e poder político, remetendo-se à estrutura e à função do aparelho estatal e pontuando os mecanismos por meio dos quais tal instituição exerce a dominação de classe:

Entendido como capacidad coercitiva, el poder político en la sociedad capitalista lo ejerce la burguesía a través del Estado, con el fin de someter a su explotación de clase a los demás grupos sociales. Es por esta razón que la teoría marxista identifica al Estado con el aparato burocrático-represivo representado por el gobierno, la burocracia, los tribunales, las prisiones, la policía, las fuerzas armadas. Esa expresión material del poder burgués se completa con el derecho, el cuerpo de normas cuya infracción activa automáticamente al aparato estatal para forzar su cumplimiento e imponer sanciones (Marini, 1976b, p. 92).

As outras duas definições estão localizadas em artigos escritos no ano de 1978, fundando-se sobre uma mesma concepção de Estado. No artigo jornalístico Reedición de "El Principito": Las dictaduras hacen girar el sol, o Estado é entendido como "[...] el resultado de las fuerzas que constituyen la sociedad real" (Marini, 1978), e, em Estado de contrainsurgencia, uma intervenção de Marini no debate La cuestión del fascismo en América Latina, tal definição é reforçada: "[...] siendo el Estado como lo es, la fuerza concentrada de la sociedad, la síntesis de las estructuras y relaciones de dominación que allí existen [...]" (Marini et al., 1978). Embora constituam definições sucintas, que não encontram maior desenvolvimento nas obras de Marini, nelas se distinguem duas visões de Estado. Enquanto a primeira delas está centrada no entendimento do Estado como um aparelho, expressão do poder burguês e de caráter burocrático-repressivo, a segunda se aproxima mais de uma concepção relacional do Estado, na medida em que ele é definido como resul-

${ }^{4} \mathrm{O}$ referido artigo foi incorporado ao livro El reformismo y la contrarrevolución: estudios sobre Chile (1976). tado das forças que constituem a sociedade. ${ }^{5}$

Avançando em relação ao entendimento do autor acerca do Estado, cumpre destacar sua interlocução com a formulação desenvolvida por Louis Althusser, em Ideologia e aparelhos ideológicos do Estado ([1970] 1980), tendo em vista que é a partir da confrontação com tal perspectiva que Marini constrói sua definição de sistema de dominação, conceito que adquire grande importância em suas formulações sobre o exercício do poder político. O autor questiona a noção ampliada de Estado, proposta originalmente por Antonio Gramsci, reformulada por Althusser, em sua concepção em torno dos aparelhos ideológicos do Estado e, recuperada, por sua vez, por Nicos Poulantzas. Fiel à concepção leninista de Estado, a qual se centra no aspecto coercitivo do aparelho estatal, o autor argumenta que a formulação de Althusser acaba diluindo aquilo que confere especificidade ao aparelho estatal, e propõe, em seu lugar, o conceito de sistema de dominação:

\footnotetext{
Esta concepción del Estado -el Estado como esfera de la coerción, para decirlo con Lenin - se diluye cuando se le borran los límites, hasta hacerlo coincidir con el sistema de dominación sobre el cual reposa. Es lo que han hecho recientemente Althusser y, en cierta medida, Poulantzas, cuando, recurriendo a algunas proposiciones de Gramsci, desarrollan el tema de los aparatos ideológicos del Estado: escuela, sindicato, partidos, iglesias, medios masivos de comunicación, familia. Por esto nos parece útil distinguir entre el sistema de dominación, que incluye el conjunto de elementos en los que una clase basa su poder, y la expresión institucional de ese poder, el Estado, tomado como cúspide del sistema de dominación (Marini, 1976b, p. 92-93).
}

Nesse caso, não é o Estado que assume um sentido ampliado, mas sim o sistema de dominação, o qual é composto pelo conjunto de elementos por meio dos quais a classe do-

${ }^{5}$ Aventamos, inicialmente, a hipótese de que essa mudança na definição de Estado de Marini estaria relacionada às suas leituras das obras de Nicos Poulantzas, já que esse mesmo movimento tem lugar no pensamento do autor grego. Entretanto, Marini apenas faz referência às obras Poder político e classes sociais ([1968] 1977), e Fascismo e Ditadura ([1970] 1972), obras nas quais tal transformação ainda não havia se concretizado. É de Fascismo e Ditadura a concepção de Estado como um aparelho. 
minante exerce seu poder. O Estado, na concepção de Marini, não apenas integra tal sistema, senão ocupa seu cume.

As diferenças entre as concepções de Estado de Marini e de Althusser se fazem notar, ademais, no que tange à relação entre o sistema de dominação (no caso de Marini) e os aparelhos ideológicos do Estado (no caso de Althusser) e o exercício da dominação de classe. Diferentemente de Althusser (1980, p. 43), para quem os aparelhos ideológicos do Estado constituem "[...] um certo número de realidades que se apresentam ao observador imediato sob a forma de instituições distintas e especializadas" e exercem, necessariamente, a função de dominação de classe, Marini considera, em seu artigo La universidad brasileña (1977d), que as instituições que compõem o sistema de dominação podem escapar ao controle da classe dominante:

Siendo indiscutible que la mayoría de las instituciones que componen lo que podríamos llamar sistema de dominación (Marini, 1976[b]) normalmente se encuentran bajo el control de la clase dominante, es decir, la clase que detenta el poder del Estado, el término aparato ideológico de Estado se presta a confusión, puesto que no permite distinguir qué instituciones del sistema de dominación escapan al control de la clase dominante ni cuándo ocurre esto (Marini, 1977d).

Marini se remete a casos como o do par$\infty$ tido revolucionário, que se propõe a derrotar a ک classe dominante, e a imprensa que combate ๙ a ideologia dominante. Para o autor, tais instituições não poderiam ser consideradas apare- le das classes dominantes, ainda as denomina como partes do sistema de dominação. Como uma instituição pertencente a tal sistema poderia se eximir do exercício da dominação? Seu argumento seria mais coerente se considerasse tais instituições como externas ao sistema de dominação, solução que tampouco resolveria um problema ainda maior, qual seja, o da possibilidade de que tais instituições subsistam no capitalismo, isto é, de que elas, como instituições capitalistas, sejam capazes de efetivamente operar em um sentido anticapitalista.

Outro elemento discutido por Marini diz respeito aos mecanismos empregados pelo Estado no exercício da dominação. Se, naquela primeira definição do autor, bem como em sua contestação às teses de Althusser, Poulantzas e Gramsci em torno da noção ampliada de Estado, ficava evidente a relevância atribuída ao aspecto coercitivo do Estado, na seguinte passagem, o autor enfatiza a imprescindibilidade da ideologia, a qual complementa e torna efetiva a dominação burguesa.

En efecto, ningún Estado puede asentarse exclusivamente en la coerción. Aún el Estado esclavista, basado en una relación de opresión-explotación casi indisfrazable y que, por eso mismo, se sostiene siempre con las armas en la mano, aún ese Estado es forzado a emplear medios no coercitivos - la costumbre, la idea de la inferioridad del esclavo, etc. - para ejercer su poder. Con el advenimiento de la sociedad burguesa, esto se acentuará, al verse la clase dominante forzada a conciliar la opresión y la explotación de las otras clases con el proyecto histórico que les propuso, centrado en las nociones de igualdad y de libertad, así como de progreso. Esa será la tarea de la ideología burguesa (Marini, 1987, grifo nosso).

Na concepção de Marini, a ideologia adquire profunda importância para a burguesia, como instrumento para o exercício do poder político. Como o autor salienta: "Ninguna clase en la historia, antes de ella [burguesía], concedió a la ideología papel tan decisivo en su modo de dominación” (Marini, 1987). Marini se refere precisamente aos efeitos ideológicos produzidos por meio do direito burguês, o qual teve, no conceito de cidadania, sua maior expressão: 
[...] la burguesía debió realizar una labor titánica, hasta convertir a la igualdad en subordinación igual de todos a la ley; a la libertad, en la libre disposición de la propia fuerza de trabajo; y al progreso, en perspectiva individual de promoción social. La piedra de toque de esa construcción ideológica, en el plano de la dominación, fue el concepto de ciudadanía - o la titularidad individual de los derechos políticos mediante el cual la burguesía escamoteó las clases sociales e hizo a cada uno partícipe aislado de la vida del Estado. El individuo ha sido confrontado así, sin ninguna defensa, al Estado, fuente y guardián del orden establecido y que cumple su función mediante el monopolio de la fuerza (Marini, 1987, grifo nosso).

Identificamos, nessa passagem, uma interlocução implícita de Marini com Poulantzas, sobretudo, no que tange à elaboração do autor grego em torno da noção de efeito de isolamento (Cf. Poulantzas, 1977), a qual se manifesta de maneira ainda mais clara em outro trecho de Marini, quando ele atenta para o papel da ideologia burguesa no bloqueio da percepção da classe trabalhadora de sua unidade como classe:

[...] más allá de la conciencia que puedan tener de su pertenencia de clase, los obreros productivos o improductivos, cualquier que sea la modalidad bajo la cual realizan su trabajo y el ámbito donde lo hacen, del mismo modo que otras clases o fracciones de clase sometidas al capital, tienen intereses comunes, cuya percepción establece la base posible de un proyecto de vida solidario. Esta es la razón por la cual todas las instituciones y mecanismos del juego político que caracterizan a la sociedad burguesa, así como sus variadas expresiones ideológicas, visan a bloquear esa percepción, a disolver la unidad latente entre los trabajadores antes que esta tome forma, a cerrarle el paso a la comprensión de los hechos reales que constituyen la esencia del orden capitalista y de su desarrollo (Marini, 1993).

Essas passagens nos permitem afirmar que, na concepção de Marini, o Estado, ao mesmo tempo em que se vale da coerção, da qual detém o monopólio legítimo (Marini, 1987), sustenta-se, também, por meio do direito, na ideologia, como mecanismo para o exercício do poder político.
Ainda no que tange ao exercício do poder político, porém, nesse momento, do ponto de vista da relação entre Estado e classes dominantes, convém ressaltar as considerações do autor a respeito da questão da autonomia relativa do Estado. Em seus artigos, El Estado en América Latina (1975) e Estado y crisis en Brasil (1977) estão suas principais reflexões em torno do tema. Situando tal discussão no campo da teoria marxista do Estado, Marini afirma que o termo relativo se refere ao fato de que, mesmo nos casos em que o Estado aparente atuar com independência frente às classes sociais, ele se mantém diretamente vinculado às classes dominantes que representa, ainda quando as políticas de Estado firam interesses daquelas classes. Segundo o autor, isso se explica porque

[...] la clase dominante deposita en el Estado, en tanto que organización por excelencia de sus intereses, la responsabilidad de conducción de sí misma. Cuando hay suficiente armonía entre las fracciones que la componen, la presencia de los intereses generales de la clase dominante se hace más visible y el margen de autonomía del Estado en lo que se refiere a su interpretación e implementación se restringe. Cuanto más se agudizan los conflictos al interior de la clase dominante, o aun si ésta encuentra ante sí una clase dominada con suficiente fuerza como para contestar su dominación, mayor es ese grado de autonomía. Es por lo que un Estado fuerte, en el sentido autoritario, es siempre una expresión de debilidad de la clase que él representa (Marini et al., 1975, p. 34).

Tal ideia é reafirmada por Marini em Estado y crisis en Brasil, quando o autor a define como uma lei geral da sociedade capitalista, estando a autonomia relativa do Estado em razão inversa à capacidade de a burguesia manter sua dominação de classe, deduzindo-se, daí, que "[...] un Estado capitalista fuerte es siempre la contrapartida de uma burguesía débil" (Marini, 1977b).

Além dos elementos já elencados, que conformam a concepção do autor sobre o Estado, cumpre destacar a relevância que este assume em suas análises sobre os processos 
revolucionários e sobre a transição socialista. Tanto em sua polêmica com Lelio Bassio, intelectual e militante socialista italiano, em Reforma y revolución: una crítica a Lelio Basso (1972), quanto em seu prólogo à obra La revolución cubana: una reinterpretación, de Vânia Bambirra, Marini (1976) explicita a centralidade que a tomada do poder do Estado adquire para a transição socialista, quando afirma que o problema central de toda política revolucionária consiste na conquista do poder político (1972) e que

La lucha por el socialismo es, fundamentalmente, una lucha política, en el sentido de que el proletariado tiene que contar con el poder del Estado para quebrar la resistencia de la burguesía a sus designios de clase e imponer a los sectores más débiles de ésta, a las capas medias burguesas, que subsisten todavía durante un cierto tiempo, una política que destruya sus bases materiales de existencia (Marini, 1976c, p. 11, grifo do autor).

É, porém, em seus escritos sobre o Chile, reunidos em El reformismo y la contrarrevolución - Estudios sobre Chile (1976), que identificamos o estudo mais aprofundado de Marini acerca da problemática do poder político. Analisando desde as condições para a chegada da Unidade Popular ao governo, passando pelas contradições do que se denominou "via chilena ao socialismo", e chegando, por fim, à análiک ๙ Marini aporta importantes elementos para se pensar a complexa relação entre poder político, Estado e classes sociais, à luz da situação concreta chilena. Partindo da particularidade do desenvolvimento capitalista dependente no país, e da configuração que a luta de classes assume a partir daí, Marini problematiza i a estratégia subjacente ao governo de Allende, segundo a qual seria possível construir uma aliança entre a pequena e a média burguesia e as classes trabalhadoras, no sentido de "[...] transformar la sociedad chilena sin romper de manera brusca el marco institucional en que se desenvuelve" (Marini, 1976b, p. 82). Segundo o autor,
La especificidad de la 'vía chilena' (término que engloba una amplia gama de posiciones) estaría en que la toma del poder no precede, sino que sigue a la transformación de la sociedad; en otras palabras, es la modificación de la infraestructura social lo que, alterando la correlación de fuerzas, impone y hace posible la modificación de la superestructura. La toma del poder se realizaría así gradualmente y, en cierto sentido, pacíficamente, hasta el punto de conformar un nuevo Estado, correspondiente a la estructura socialista que se habría ido creando (Marini, 1976b, p. 86-87, grifo do autor).

Marini, apoiando-se nas experiências revolucionárias do século XX, e nas contradições e limitações ensejadas pelo modelo político chileno, contrapõe-se àquela estratégia, enfatizando que a transformação da economia capitalista monopolista em uma economia socialista somente poderá ter lugar com a apropriação, pelos trabalhadores, do aparelho de Estado, como afirma na seguinte passagem:

La verdadera solución a los problemas planteados a las masas por la acumulación del capital es por tanto el surgimiento de un nuevo sistema de dominación, capaz de reorientar el desarrollo de las fuerzas productivas. En otros términos, los problemas que plantea a las masas la acumulación capitalista sólo se resuelven con la revolución política (Marini, 1976b, p. 84, grifo do autor).

Reivindicando uma vez mais Lênin, Marini salienta que a tomada do poder se apresenta como condição para o processo de transformação social, constituindo-se como um traço peculiar da revolução socialista:

Teoría y práctica van, pues, de la mano cuando se trata de establecer una determinada jerarquía entre los dos polos de la relación considerada: toma del poder - transformación social. El desplazamiento radical y - como subraya Lenin - violento de la burguesía por el proletariado en el poder político, como condición para llevar a cabo la transformación social, aparece así como un rasgo peculiar de la revolución socialista, que la diferencia netamente de la revolución burguesa (Marini, 1976b, p. 92).

Elencamos aqui alguns dos principais elementos que compõem a concepção de Marini sobre Estado, destacando reflexões presen- 
tes tanto em suas análises mais gerais, quanto em seus estudos sobre as realidades concretas latino-americanas. Passamos agora a uma investigação acerca do que consideramos como os principais aportes do autor à reflexão em torno das particularidades do Estado dependente.

\section{APONTAMENTOS SOBRE O CA- RÁTER DEPENDENTE DOS ESTA- DOS LATINO-AMERICANOS}

A reflexão mais sistemática do autor acerca do caráter dependente dos Estados latino-americanos encontra-se em dois de seus artigos, sendo eles El Estado en América Latina (1975), fruto de uma mesa redonda da qual participaram, além de Marini, Agustín Cueva, Arnaldo Córdova, Clodomiro Almeyda e Sergio Bagú, e Estado y crisis en Brasil (1977). Enquanto, no primeiro, Marini constrói uma periodização do processo de formação e consolidação dos Estados latino-americanos, relacionando-o ao desenvolvimento capitalista dependente e à articulação das classes dominantes no bloco no poder, ${ }^{6}$ no segundo, a discussão se concentra nas relações entre Estado, burguesias dependentes e burguesias imperialistas, ganhando destaque a argumentação do autor em torno da questão da autonomia relativa do Estado frente a tais classes.

O primeiro ponto a ser salientado diz respeito ao emprego do conceito de Estado dependente. Embora o autor não se ocupe propriamente em formular uma definição, ele faz uso, nesses dois artigos, do adjetivo dependente para qualificar os Estados latino-americanos. Isso ocorre em dois momentos: no primeiro, quando, depois de discutir a relação entre a debilidade das burguesias dependentes e a força dos Estados nos países dependentes, contrapõe-se ao conceito de burguesia de Estado:

${ }^{6}$ Ainda que Marini não empregue o conceito de bloco no poder nesses dois artigos, consideramos que tal conceito expressa com maior precisão os argumentos por ele desenvolvidos.
Sin embargo, por mucho que esto nos permita entender ciertas particularidades del Estado dependiente latinoamericano, no nos debe inducir a confusiones, como el que suscita el concepto de 'burguesía de Estado', que vienen aplicando para Latinoamérica algunos estudiosos (Marini et al., 1975, p. 35, grifo do autor).

E, no segundo, ao discutir os nexos entre o Estado dependente e a burguesia imperialista:

Finalmente, en la medida en que la situación que acabamos de indicar implica que el Estado dependiente se encuentra referido también a la burguesía imperialista, las contradicciones que se establecen en el seno de ésta operan en el sentido de ampliar su autonomía relativa, ahora en relación a la misma burguesía imperialista (Marini, 1977b, grifo nosso).

Ao buscar precisar as particularidades do Estado dependente latino-americano, Marini faz questão de ressaltar que tal Estado está sujeito às determinações gerais do Estado capitalista, por se constituir como órgão de dominação da burguesia, subordinando "[...] toda la sociedad al império del capital” (Marini et al., 1975, p. 9). Nesse sentido, sua função geral é a mesma de todos os Estados no capitalismo, qual seja, a de garantir a reprodução do capital e a dominação da classe burguesa. Suas características, entretanto, distinguem-se, em diversos aspectos, dos Estados que se formaram nos países europeus e nos Estados Unidos.

No que tange à formação dos Estados latino-americanos, depreende-se da análise realizada por Marini que, para o autor, tais Estados conformaram-se, desde sua gênese, ${ }^{7}$ como Estados capitalistas, argumento que fica evidente em três momentos de seu artigo El Estado en América Latina: 1) quando o autor ressalta que o desajuste entre as relações de produção e as formas políticas, nos países latino-americanos, representava uma contradição apenas aparente, já que, na base do Estado, se encontravam interesses burgueses perfeita-

${ }^{7}$ Marini entende que a gênese dos Estados latino-americanos somente se dá a partir dos processos de independência na região, tendo em vista que os Estados coloniais constituíam mais bem apêndices do Estado metropolitano (Marini et al., 1975). 
mente definidos, e o motor da economia estava constituído por áreas nas quais imperavam relações de tipo capitalista; 2) quando afirma que o Estado capitalista, na América Latina, começou a se constituir em 1840; 3) quando caracteriza o Estado oligárquico-burguês como um Estado capitalista, forma política correspondente à economia exportadora. Nesse sentido, entendemos que, ainda que ele problematize o desajuste entre as formas econômicas e as formas políticas que caracterizam os períodos de transição, na prática, ele reconhece que há uma correspondência entre ambas no caso latino-americano, já que salienta que as relações de tipo capitalista eram o motor daquelas economias, e atribui ao Estado formado após as independências latino-americanas um caráter capitalista.

Tais desajustes são interpretados pelo autor à luz da explicação sobre os períodos de transição, formulada originalmente por Étienne Balibar ${ }^{8}$ ([1965] 1969), segundo a qual tais períodos são marcados por um aparente desajuste entre as formas econômicas e políticas, o que explicaria, de acordo com Marini, “[...] la llamada 'supervivencia' de relaciones de producción aparentemente atrasadas respecto al desarrollo global de la sociedad, así como el sostenimiento de formas políticas sin correspondencia visible con el modo de producción dominante” (Marini et al., 1975, p. 10). Em-

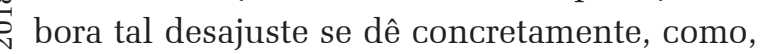
凶ં por exemplo, na persistência de relações de produção escravistas no Brasil na segunda metade do século XIX e de relações "semifeudais" nos demais países latino-americanos, frente a formas políticas burguesas, este apenas implica uma contradição aparente, segundo Marini, uma vez que "En la base del Estado encontramos intereses burgueses perfectamente definidos y el motor de la economía [...] está constituido por áreas en que imperan ya relaciones de tipo capitalista” (Marini et al., 1975, p. 10).

Embora não se encontre, nesse artigo, qualquer referência a Balibar, sabemos, a partir da leitura de Reforma y revolución: una crítica a Lelio Basso, que sua fonte reside na formulação daquele autor, já que Marini cita, em uma nota de rodapé, a definição de Balibar sobre os períodos de ङ transição (Cf. Marini, 1974).
Chamamos a atenção para um elemento que explica, em grande medida, esse argumento de Marini, qual seja, seu entendimento acerca da interação entre as determinações internas e externas. Para o autor, o capitalismo latino-americano existiria com mais força em seu exterior do que em seu interior, querendo com isso dizer que ele modifica e aperfeiçoa, primeiramente, suas relações com a economia internacional, para, em seguida, adequar suas relações internas àquelas (Marini et al., 1975). Nesse argumento, encontramos a raiz de sua interpretação acerca do caráter capitalista do Estado latino-americano. Na medida em que a integração das economias latino-americanas no mercado mundial se faz nos marcos do processo de acumulação capitalista, é essa relação que condicionará a estrutura interna daquelas economias, ainda que as relações de produção se assentem em outras formas que não a capitalista. É nesse sentido que é possível localizar, na perspectiva de Marini, a formação do Estado capitalista latino-americano em 1840, mesmo quando não se podia falar ainda de uma classe burguesa propriamente.

Em outra passagem, associada à gestação do Estado burguês, a dominância do nível externo sobre o interno também se faz notar, tendo em vista que Marini acentua que: "Son las condicionantes nacionales, más que las internacionales, las que determinan la duración de esse processo en cada país, aunque sean las condiciones internacionales las que lo impulsan en todo el continente" (Marini et al., 1975, p. 10, grifo nosso). Ainda que, nesse último excerto, o autor esteja ressaltando a relevância das condicionantes nacionais, à medida que delas depende a duração do processo de formação do Estado burguês, a origem de tal movimento é fruto de impulsos externos às formações sociais latino-americanas.

No que tange à formação da burguesia como classe, Marini considera que, nesse processo, reside uma das especificidades do Estado latino-americano, uma vez que suas características capitalistas se manifestam mais 
rapidamente do que nos casos europeu e estadunidense, tendo em vista que sua gênese se dá em um momento no qual o capitalismo se consolidava como modo de produção dominante na Europa, e muitos Estados europeus já se haviam conformado. De acordo com o autor,

[...] la clase capitalista en América Latina - además de estar permeada por el capital internacional - tiene ante sus ojos, antes aún de haber perfilado plenamente su carácter de clase, el modelo de dominación burguesa en aquellas sociedades a las cuales está ligada por lazos económicos y culturales (Marini et al., 1975, p. 9).

Segundo Marini, a formação do Estado burguês latino-americano deve ser entendida como um processo de luta entre as distintas frações das classes dominantes, na tentativa de impor sua hegemonia sobre as demais. É precisamente tal elemento que orienta sua periodização dos Estados na América Latina. O autor, além de distinguir entre duas formas distintas de Estado - o Estado oligárquico-burguês e o Estado burguês -, faz referência ao populismo, como uma forma de transição entre aqueles dois Estados e o Estado militar, produto da crise do Estado burguês. Conforme evidenciamos anteriormente, todas essas formas de Estado, na perspectiva de Marini, correspondem ao mesmo tipo de Estado, o Estado capitalista, ${ }^{9}$ embora a diferenciação elaborada por Marini entre o que ele chama de formas políticas assumidas pelo Estado não seja objeto de elucidação. Se, no caso do Estado oligárquico-burguês e do Estado burguês, vislumbramos uma classificação segundo a configuração do bloco no poder, ou, mais precisamente, a(s) classe(s) que exerce $(\mathrm{m})$ a hegemonia no bloco no poder, nos outros dois casos, do populismo e do Estado militar, tal critério não é seguido.

O Estado oligárquico-burguês, compreendido por Marini como a forma política correspondente à economia exportadora, forma-se a partir de 1840, como

\footnotetext{
${ }^{9}$ Apoiamo-nos na elaboração de Poulantzas acerca dos ti-
} pos de Estado (Cf. Poulantzas, 1977).
[...] un Estado capitalista que impone al conjunto de la sociedad el interés de las fracciones de la clase dominante en mejores condiciones para promover la vinculación a la economía mundial, concediendo participación minoritaria a las demás fracciones dominantes locales y aplastando políticamente a la inmensa masa de campesinos y artesanos ${ }^{10}$ (Marini et al., 1975, p. 11).

Já na década de 1880, tal Estado passa por transformações - reformas eleitorais, reformas na educação, etc. - cujo significado está associado, segundo o autor, a uma ampliação progressiva da aliança de classes, maior no caso da burguesia, e menor no caso dos setores médios urbanos, burgueses e pequeno-burgueses. A conversão daquele Estado em Estado burguês se dará, entretanto, apenas a partir da década de 1930, com a concretização da aliança ou compromisso entre a ascendente burguesia média, industrial e comercial, e a antiga burguesia proprietária de terra e mercantil. No bojo desse processo de transformação, estaria, segundo o autor, o populismo, ${ }^{11}$ como a forma de transição do Estado oligárquico-burguês, para o Estado burguês, que se refletiu na criação de novos mecanismos de dominação sobre as classes proletárias camponesas e pequeno-burguesas, mecanismos esses que, se, por um lado, ampliavam sua participação na vida política, significavam, por outro, o aprofundamento do controle político e ideológico da burguesia $^{12}$ (Marini et al., 1975).

${ }^{10}$ Nessa passagem, ao lado dos camponeses e artesãos, poderiam ser incluídos os escravos, já que, em muitos países latino-americanos, a escravidão ainda não havia sido abolida naquele momento.

${ }^{11}$ A discussão sobre populismo por Marini ganha maior desenvolvimento em Subdesarrollo y revolución, associada à sua análise sobre o estabelecimento de regimes de tipo bonapartista. Marini classifica como exemplos de regimes bonapartistas, o governo de Perón, na Argentina, os governos de Vargas, Jânio Quadros ("bonapartismo carismático") e João Goulart ("bonapartismo de massas"), no Brasil. Para uma caracterização mais detida desses governos e de sua definição como bonapartista pelo autor, consultar Ma$\operatorname{rini}(1977 a)$.

${ }^{12}$ Nessa periodização realizada por Marini, o autor não faz qualquer menção ou associação do processo de formação do Estado burguês à revolução burguesa nos países latino-americanos. Em Subdesarrollo y revolución, entretanto, Marini afirma que a revolução burguesa, na América Latina, não ocorreu segundo os cânones europeus, o que estaria relacionado às condições objetivas dentro das quais se desenvolveu a industrialização latino-americana (Cf. Marini, 1977a). 
O autor encerra sua periodização referindo-se ao Estado militar, fruto da crise política que se instaurou no Estado burguês, e que implicou a mudança de regime político em diversos países latino-americanos. Enfatizando os casos brasileiro e chileno, o autor salienta que tal Estado se sustenta por meio de uma repressão generalizada e do recurso a mecanismos de dominação oriundos do antigo arsenal fascista, como forma de legitimação. Outra característica distintiva desse Estado, e, ao mesmo tempo, central, diz respeito à diferenciação que tem lugar na classe burguesa, com a ascensão do grande capital, em estreita associação com o capital estrangeiro, à hegemonia do bloco no poder. Marini afirma, ademais, que é precisamente o grau de desenvolvimento da burguesia nacional e seu grau de integração com o capital estrangeiro que distinguirão os Estados latino-americanos nessa nova fase do Estado burguês na região.

Conforme anunciamos, o tema da autonomia relativa do Estado também será analisado por Marini à luz das especificidades latino-americanas e será entendido pelo autor como "[...] resultado de contradicciones de clases inherentes a la situación de dependencia” (Marini, 1977b). Embora constitua um traço característico de todos os Estados, na ótica da teoria $\infty$ marxista do Estado, na perspectiva de Marini, ๖े nas sociedades dependentes latino-americanas, ֻ tal elemento se manifesta de maneira ainda mais đ aguda, o que se deve, na concepção do autor, à mucho más poderosa” (Marini et al., 1975, p. 34). A força do Estado, por seu turno, justifica-se, segundo Marini, em razão do processo permanente de superexploração dos trabalhadores que tem lugar no âmbito daquelas economias, o que exige um Estado forte, sobretudo no que se refere à sua capacidade repressiva (Marini et al., 1975).

É no marco da vinculação entre as burguesias latino-americanas e as burguesias imperialistas e das contradições daí advindas que podemos vislumbrar as particularidades da autonomia relativa do Estado dependente, tendo em vista que é precisamente o Estado que intermedeia o processo de integração entre elas. Marini faz referência ao papel cumprido pelo Estado em tal processo em La acumulación capitalista mundial y el subimperialismo, ao relacionar o desenvolvimento da integração dos sistemas de produção ao fortalecimento do Estado nacional nos países dependentes, afirmando que

[...] el capital exportado por los países imperialistas a las zonas dependientes exige allí del Estado nacional una capacidad creciente en materia de obras de infraestructura, defensa del mercado interno, negociaciones financieras y comerciales con el exterior, financiamiento interno y creación de condiciones políticas (en particular en el terreno laboral) favorables a la inversión extranjera (Marini, 1977c).

Na medida em que essa integração não se faz sem contradições, erigindo-se sob a égide de uma cooperação antagônica, ${ }^{13}$ a burguesia nativa, como prefere denominar Marini em vez de burguesia nacional -, vê-se frente à necessidade de se apoiar no Estado, no sentido de garantir sua preservação, o qual, ao atuar como intermediador, tem sua autonomia relativa aumentada em relação à burguesia nativa, ampliando sua capacidade de ação na econo-

${ }^{13}$ Marini emprega o conceito de cooperação antagônica, formulado pelo marxista alemão August Thalheimer, para definir, em Subdesarrollo y revolución, o caráter assumido pela relação entre a burguesia dos países dependentes latino-americanos e o imperialismo na fase de integração imperialista, evidenciando a existência de diferenciações e mesmo oposições de interesses entre aquelas burguesias e as burguesias imperialistas. Tal conceito assumirá, ademais, grande importância em sua formulação acerca do subimperialismo. 
mia dependente. A autonomia relativa do Estado também se manifesta em relação às burguesias imperialistas, associada, nesse caso, às contradições interimperialistas que têm lugar no seio daquelas burguesias. À medida que tais contradições se agudizam, o Estado dependente vê sua autonomia relativa frente às burguesias imperialistas aumentar. Essas contradições, entretanto, não se circunscrevem, como enfatiza Marini, apenas ao plano do mercado mundial, convertendo-se, mediante a integração imperialista, em contradições internas das próprias economias dependentes (Marini, 1977b).

Realizados alguns apontamentos a respeito das formulações de Marini sobre o Estado dependente, avançamos agora em direção a duas contribuições significativas do autor ao estudo do Estado nos países dependentes latino-americanos: sua análise sobre o subimperialismo e sobre o Estado de contrainsurgência.

\section{O subimperialismo como uma particulari- dade dos estados dependentes}

No presente subitem, dedicamos atenção a um conceito que ocupou importante lugar nos escritos de Marini - o de subimperialismo, ${ }^{14}$ como expressão própria de uma fase do desenvolvimento capitalista dependente.

O subimperialismo, entendido por Marini (1977c) não apenas como uma categoria, mas também como um fenômeno histórico, tem sua emergência localizada na fase imperialista de integração dos sistemas produtivos, cujos impactos, na América Latina, se farão sentir, sobretudo, por meio da intensa penetração de capitais estrangeiros em seus setores industriais. Tal como descrevemos no primeiro item, esse momento, que representa uma nova etapa da dependência latino-americana, significou a agudização das contradições que mar-

${ }^{14}$ Para um estudo aprofundado sobre o conceito de subimperialismo na obra de Ruy Mauro Marini (Cf. Luce, 2011). cavam o ciclo do capital daquelas economias, sobretudo no que diz respeito à relação entre a produção e o consumo, implicando um divórcio ainda mais profundo das necessidades da maioria da população daqueles países. A incorporação de novas tecnologias aos meios de produção, ainda que tenha possibilitado um aumento de produtividade nas economias dependentes, não produziu, como efeito, uma redução do recurso à superexploração do trabalho, razão pela qual a capacidade de consumo dos trabalhadores se manteve restringida. Nesse sentido, a produção industrial latino-americana se vê diante de graves problemas de realização, para os quais ela deverá buscar solução. É no bojo dessa limitação que se desenvolverão mecanismos para contra-arrestar tal tendência, como a exportação de manufaturas, o aumento da capacidade de compra do Estado e o incremento do consumo suntuário, através da distribuição regressiva dos salários (Marini, 1977a). Tais mecanismos, empregados por diferentes países latino-americanos, assumem um diferente caráter quando conjugados com uma política expansionista, podendo, somente a partir daí, serem reconhecidos como partes de uma política subimperialista, segundo a concepção de Marini.

Produto, portanto, tanto da reestruturação do sistema capitalista mundial e das leis próprias da economia dependente,,$^{15}$ o subimperialismo é concebido por Marini a partir da articulação entre sua dimensão econômica e política, ${ }^{16}$ na medida em que

[...] implica dos componentes básicos: por un lado, una composición orgánica media en la escala mundial de los aparatos productivos nacionales y, por

15 Sendo elas, a superexploração do trabalho, o divórcio entre as fases do ciclo do capital, a integração do capital nacional ao capital estrangeiro e a monopolizaçãoacentuada em favor da indústria suntuária (Marini, 1977a).

${ }^{16}$ Como o próprio autor ressaltaemmais de umapassagem, não é possível prescindir da dimensão política do subimperialismo: “[...] la caracterización del subimperialismo va más allá de la simple economía, no pudiendo llevarse a cabo, si no se recurre también a la sociología y a la política" (Marini, [1972] 2007, p. 136); "Hemos dicho ya, en otras oportunidades, que la concreción histórica del subimperialismo no es una cuestión meramente económica" (Marini, 1977a, p. 19-20, grifo nosso). 
otro lado, el ejercicio de una política expansionista relativamente autónoma, que no sólo se acompaña de una mayor integración al sistema productivo imperialista sino que se mantiene en el marco de la hegemonía ejercida por el imperialismo a escala internacional (Marini, 1977c).

Embora Marini elabore uma definição geral sobre o subimperialismo, ela se baseia, fundamentalmente, na experiência histórico-concreta brasileira, já que apenas o Brasil foi capaz de reunir aquelas condições, na perspectiva do autor. Isso não significa, entretanto, que tal possibilidade estivesse vedada a outros países, ${ }^{17}$ como salienta o autor em Dialéctica de la dependencia: "[...] el subimperialismo [...] no es un fenómeno específicamente brasileño ni corresponde a una anomalía en la evolución del capitalismo dependiente. [...] es tan sólo una forma particular que asume la economía industrial que se desarrolla en el marco del capitalismo dependiente" (Marini, [1972] 2007, p. 136).

Nessa mesma passagem, Marini explicita os elementos que permitiram que o Brasil se conformasse como um país subimperialista:

Es cierto que son las condiciones propias a la economía brasileña, que le han permitido llevar lejos su industrialización y crear incluso una industria pesada, así como las condiciones que caracterizan a su sociedad política, cuyas contradicciones han dado

Sm seu prefácio à quinta edição de Subdesarrollo y rev- olución, o autor reconhece que do ponto de vista mera-

mente econômico, de oitenta países dependentes por ele

U considerados, apenas seis detinham uma composição

orgânica mais alta, cuja produção industrial incidia em

aproximadamente um terço do produto bruto. Dentre eles

estavam três países latino-americanos, Brasil, Argentina e

\&ु México (Marini, 1977a). monopólios industriais e ao capital financeiro nacional e internacional (Marini, 1977a), sua emergência se dá no governo de Castelo Branco, e enfrentará resistências tanto de ordem interna, quanto externa. Se, no plano externo, as contradições estavam relacionadas ao fato de tal política estar engendrada pela dominação imperialista, estabelecendo-se sobre as bases de uma cooperação antagônica, bem como às disputas interburguesas no âmbito regional, especificamente entre a burguesia brasileira e a argentina, no plano interno, produziu atritos e fissuras entre as frações da burguesia brasileira, entre a burguesia e o regime militar, e entre as classes dominantes e as classes dominadas.

Em sua análise sobre o subimperialismo brasileiro, Marini chama a atenção para o destacado papel do Estado na viabilização dessa política. Ao mesmo tempo em que evidencia sua capacidade para criar e subsidiar a demanda para a produção, assegurar campos de investimento no exterior, por meio das empresas estatais, de créditos governamentais ou de garantias a operações privadas na América Latina e África (Marini, 1977b), chamando atenção, inclusive, para o estímulo proporcionado por tal Estado à indústria nuclear e à indústria bélica, explicita sua participação nos processos políticos internos de alguns países latino-americanos, como foram os casos de Bolívia, Chile e Uruguai, apoiando movimentos contrarrevolucionários (Marini, [1978] 2005). Situando essa posição do Estado brasileiro no marco da cooperação antagônica, Marini afirma que se trata, antes, de uma política de subpotência ${ }^{18}$ do que de uma potência propriamente dita, tendo em vista os limites dentro dos quais está circunscrito o subimperialismo brasileiro, ou seja, o de se constituir como "[...] extensión indirecta del imperialismo norteamericano [...] $]^{19 ”}$ (Marini, 1977a, p. 76).

${ }^{18}$ Marini ressalta, entretanto, que o conceito de subpotência não substitui o de subimperialismo (Cf. Marini, 1977c).

19 Tal elemento representa, antes, um traço conjuntural de manifestação do subimperialismo brasileiro, do que uma característica constitutiva da categoria de subimperial- 
No que tange à problemática aqui discutida, entendemos que o conceito de subimperialismo de Marini lança luz sobre a existência de graus distintos de poder entre os Estados dependentes latino-americanos, evidenciando, ao mesmo tempo, a articulação entre uma determinada fase do desenvolvimento capitalista e a construção de uma política de expansão regional por parte do Estado brasileiro.

\section{Estado de contrainsurgência}

Passamos ao último ponto deste artigo, aquele que concentra, em nossa perspectiva, a principal contribuição de Marini a respeito do Estado dependente latino-americano. Trata-se de sua formulação em torno do conceito de Estado de contrainsurgência. Forjado na segunda metade da década de 1970, tal conceito aparece primeiramente em alguns artigos jornalísticos de Marini, alcançando, porém, o ponto mais alto de sua sistematização na intervenção do autor no seminário Las fuentes externas del fascismo: el fascismo latinoamericano y los intereses del imperialismo, ocorrido em 1978, no México, o qual deu origem ao dossiê La cuestión del fascismo em América Latina, contando, ademais, com as contribuições de Pío García, Agustín Cueva e Theotônio dos Santos. Embora essa elaboração de Marini não tenha recebido a mesma atenção que os conceitos de superexploração do trabalho e de subimperialismo por parte de seus estudiosos, ${ }^{20}$ ela representa um percurso necessário no entendimento de sua análise sobre a nova fase da dependência latino-americana, cuja expressão política foi precisamente o Estado de contrainsurgência.

ismo. Agradecemos a indicação de Mathias Luce acerca desse ponto.

${ }^{20}$ Cumpre destacar que Jaime Osorio (2016) recupera as formulações de Marini sobre o Estado de contrainsurgência em seus escritos, quando analisa os Estados latino-americanos durante as décadas de 1960 e 1970. Recentemente, no dossiê publicado pela revista Cadernos Cemarx, há um artigo de Iván López Ovalle e Mateo Crossa Niell dedicado à discussão do Estado no pensamento de Marini, no qual os autores dão ênfase às concepções de Marini de Estado de contrainsurgência e de Estado de quarto poder (Cf. Ovalle; Niell, 2016).
Concebido à luz dos golpes militares que tiveram lugar na América Latina nas décadas de 1960 e 1970 - Brasil, Bolívia, Argentina, Chile, Peru, Uruguai, Nicarágua -, tal conceito significou uma mudança interpretativa de Marini a respeito dos regimes políticos estabelecidos naqueles países, uma vez que, até aquele momento, seus escritos acerca dessa problemática estavam construídos sob a chave analítica do fascismo. ${ }^{21}$ Com isso, não queremos dizer que o autor tenha incorrido em uma tradução mecânica do conceito, mas sim que sua formulação sobre o Estado de contrainsurgência implica um passo adiante em sua análise, já que enfatiza as particularidades do processo vivido pelos países dependentes, em um espaço-tempo distinto, e enfrentando condições bastante diversas daquelas experimentadas pelos países europeus na primeira metade do século XX.

$\mathrm{O}$ primeiro ponto que merece ser assinalado é que tal conceito não se refere apenas às ditaduras militares. Ele tem um escopo mais amplo, pois corresponde ao processo contrarrevolucionário latino-americano, abrangendo também regimes civis, como afirma Marini, ao se referir ao caso venezuelano. Na concepção do autor, o Estado de contrainsurgência "[...] es el Estado corporativo de la burguesía monopólica y las Fuerzas Armadas, independientemente de la forma que asuma ese Estado, es decir, independientemente del régimen político vigente" (Marini et al., 1978, grifo do autor). Produto da contrarrevolução latino-americana, a conformação desse Estado é entendida pelo autor a partir de três dimensões fundamentais: a mudança na estratégia global estadunidense, dentro da qual se insere a doutrina de contrainsurgência; as transformações no seio do bloco no poder nos países latino-americanos; e a resistência protagonizada pelas classes populares. Analisemos mais detalhadamente os argumentos de Marini.

Quanto à primeira delas, o autor a situa no âmbito das modificações na balança de po-

${ }^{21}$ Consultar, sobretudo, os escritos de Marini sobre o golpe militar chileno (Cf. Marini, 1976b). 
der entre Estados Unidos e União Soviética, na direção de um maior equilíbrio entre os dois países. Diante dessa nova situação, Marini acentua a formulação de uma nova estratégia estadunidense para enfrentar os movimentos revolucionários, conduzida a partir do governo de John F. Kennedy, cujo centro residia na doutrina de contrainsurgência. Ancorada em três consignas, o aniquilamento do inimigo, a conquista de bases sociais e a institucionalização, tal política teve, na América Latina, um de seus principais laboratórios, contando com a colaboração ativa das classes dominantes locais e constituindo-se como ponto de sustentação dessa política.

Voltando-se precisamente para as classes dominantes latino-americanas, Marini atenta para os impactos da integração imperialista dos sistemas de produção no bloco no poder, e, consequentemente, no próprio Estado latino-americano. Os investimentos diretos de capital estrangeiro, a subordinação tecnológica e a penetração financeira que caracterizaram esse processo, na América Latina, impulsionaram o desenvolvimento de uma burguesia monopolista naqueles países, estreitamente vinculada à burguesia imperialista, sobretudo, à estadunidense. Às contradições particulares do capitalismo dependente, da qual a supeœ rexploração do trabalho é uma das principais 穴 classes e frações de classes latino-americanas, como resultado da maior centralização de capital e da proletarização da pequena burguesia que a integração imperialista enseja. Como reconhece Marini,

El resultado de ese proceso es la ruptura, el abandono de lo que había sido, hasta entonces, la norma en América Latina: el Estado populista, es decir, el 'Estado de toda la burguesía', que favorecía la acumulación de todas sus fracciones (aunque éstas aprovecharan desigualmente los beneficios puestos a su alcance). En su lugar, se crea un nuevo Estado, que se preocupa fundamentalmente de los intereses de las fracciones monopólicas, nacionales y extranjeras, y establece, pues, mecanismos selectivos para favorecer su acumulación; las demás fracciones burguesas

\begin{abstract}
deben subordinarse a la burguesía monopólica, quedando su desarrollo en estricta dependencia del dinamismo que logre el capital monopólico, mientras que la pequeña burguesía, aunque sin dejar de ser privilegiada en la alianza de clases en que reposa el nuevo poder burgués, es forzada a aceptar una redefinición de su posición, pierde importancia política y queda, ella también totalmente subordinada, con sus condiciones de vida vinculadas a las iniciativas y al dinamismo de la burguesía monopólica (Marini et al., 1978, grifo do autor).
\end{abstract}

Tendo essa passagem como referência, vemos como o Estado de contrainsurgência se inscreve na periodização de Marini. Podemos afirmar que tal Estado representaria, na percepção do autor, a consolidação do Estado burguês na América Latina. Se, em sua exposição em El Estado en América Latina, Marini evidenciava que o Estado populista foi um Estado de transição entre o Estado oligárquico-burguês e o Estado burguês, e, nesse momento, afirma que o Estado de contrainsurgência sucedeu o Estado populista, entendemos que o Estado de contrainsurgência qualifica a forma assumida pelo Estado burguês naquela fase da dependência latino-americana, de integração imperialista dos sistemas de produção, e frente à política contrarrevolucionária que impactou profundamente aqueles países.

É, portanto, sobre a base concreta de rupturas e cisões no interior do bloco no poder e de hegemonia das frações monopolistas nacionais e estrangeiras ${ }^{22}$ que se conforma o Estado de contrainsurgência, o qual se defronta, ademais, com a ascensão e a radicalização de movimentos populares camponeses e operários, frente aos quais, sobretudo após a experiência revolucionária cubana de 1959, oporá uma forte e violenta reação.

Estabelecidas as bases sobre as quais se estrutura o Estado de contrainsurgência, avan-

${ }^{22}$ Ao explicitar os conflitos que têm lugar no interior do bloco no poder, Marini adverte que mesmo sendo um "Estado do capital monopolista", no sentido de que é essa fração que exerce a hegemonia, tal fato não exclui a participação das demais frações burguesas.Sua preocupação, ao ressaltar esse ponto, estava em esclarecer que tal Estado, ainda que hegemonizado pela fração monopolista, garantia a exploração e a dominação da classe burguesa em seu conjunto (Cf. Marini et al., 1978). 
cemos rumo à sua caracterização. De acordo com Marini, seu traço distintivo residiria na existência de dois ramos centrais de decisão no poder executivo. Marcado por um poder executivo hipertrofiado, ${ }^{23}$ seus ramos centrais de decisão estão articulados pela combinação entre um ramo militar e outro econômico, como descreve o autor:

De un lado, la rama militar, constituida por el Estado Mayor de las Fuerzas Armadas, que expresa a la institución militar al nivel de la toma de decisiones y que reposa sobre la estructura vertical propia a las Fuerzas Armadas; el Consejo de Seguridad Nacional, órgano deliberativo supremo, en el que se entrelazan los representantes de la rama militar con los delegados directos del capital; y los órganos del servicio de inteligencia, que informan, orientan y preparan el proceso de toma de decisiones. De otro lado, la rama económica, representada por los ministerios económicos, así como las empresas estatales de crédito, producción y servicios, cuyos puestos clave se encuentran ocupados por tecnócratas civiles y militares. Así, el Consejo de Seguridad Nacional es el ámbito donde confluyen ambas ramas, entrelazándose, y se constituye en la cúspide, el órgano clave del Estado de contrainsurgencia (Marini et al., 1978, grifo do autor).

Ainda de acordo com o autor, a tomada de decisões tem seu epicentro justamente no poder executivo, afastando-se da influência das demais instâncias de poder, a legislativa e a judiciária. Ao destacar o papel cumprido pelas Forças Armadas no Estado de contrainsurgência, Marini faz questão de pontuar que não se trata de uma "burguesia de Estado", nem de uma classe social propriamente dita. Para o autor, os tecnocratas que ocupam a gestão do Estado, tanto civis, quanto militares, constituem-se como a representação política do capital, "[...] un cuerpo de funcionarios cuya voluntad económica y política es rigurosamente la de la clase a que sirve" (Marini et al., 1978). Nesse sentido, o exercício do poder político é compartilhado, segundo o autor, entre as Forças Armadas e a burguesia monopolista. Ao

${ }^{23}$ Marini ressalta que a hipertrofia do Executivo não constitui elemento distintivo desse Estado em relação ao "moderno Estado capitalista" (Marini et al., 1978). recorrer às Forças Armadas como mecanismo último de defesa do poder burguês, tal burguesia confere a esse aparelho especial do Estado, segundo Marini “[...] la misión de solucionar el problema; está, pues, pasando del terreno de la política al de la guerra” (Marini et al., 1978).

Como já advertimos, Marini se ocupa de distinguir o Estado de contrainsurgência latino-americano do Estado fascista europeu, afirmando que, embora ambos correspondam a formas particulares de contrarrevolução burguesa, recorrendo ao terrorismo de Estado como mecanismo de enfrentamento a seus opositores, há elementos que os diferenciam significativamente. Os próprios processos de contrarrevolução, dos quais tais Estados são produtos, lhes imputam traços característicos, como é o caso da relação entre tal Estado e as classes trabalhadoras. No caso do fascismo europeu, o Estado que se conformou a partir da crise do sistema de dominação não foi capaz de excluir a classe trabalhadora da vida política por meio da força, tendo sido necessário isolá-la ideológica e politicamente, em razão de seu desenvolvimento político, segundo Marini (1976a). Como afirma o autor, tal processo implicou que "La vieja democracia liberal y todo lo que legitimaba la dominación burguesa debieron ser cuestionados, en nombre de nuevos mitos que aseguraran que esa dominación no se cuestionara en los hechos mismos" (Marini, 1976a, p. 2). Já no caso do processo de contrarrevolução na América Latina, ${ }^{24}$ o Estado não pôde contar com um apoio real das classes trabalhadoras, o que explica, de acordo com o autor, o fato de que "La violación de los principios más elementales de la ideología burguesa tiene que hacerse en nombre de esa ideología” (Marini, 1976a, p. 2). Essa diferen-

${ }^{24}$ Na perspectiva de Marini, o processo de contrarrevolução latino-americana, a despeito dos traços particulares que assume em cada sociedade concreta, desenvolve-se inicialmente sob um período de desestabilizacão, no qual as forças reacionárias procuram, de um lado, reunir o conjunto da burguesia, e, de outro, provocar a divisão no seio do movimento popular; passando, em seguida, à concretização de golpes de Estado, conduzidos pelas Forças Armadas, e à instauração de ditaduras militares (Marini et al., 1978). 
ça é explicitada com maior clareza na seguinte passagem:

A diferencia del fascismo europeo, que fue capaz de arrastrar a las amplias masas pequeñoburguesas y de morder incluso al proletariado, ganando allí cierto grado de apoyo entre trabajadores desempleados y hasta obreros en actividad, la burguesía monopólica en América Latina no puede pretender reunir verdadera fuerza de masas, que le permita enfrentar políticamente, en las urnas y en las calles, al movimiento popular. Por esto, se da como meta el restablecimiento de las condiciones de funcionamiento del aparato estatal, aunque sea temporalmente, para poder accionarlo en su provecho (Marini et al., 1978).

Outros dois elementos enunciados por Marini dizem respeito, por um lado, ao discurso ideológico de defesa da democracia burguesa e do Estado burguês, que tem lugar no processo de contrarrevolução latino-americano, diferentemente de sua negação por parte do discurso fascista europeu, e, por outro, o objetivo da política de desestabilização levada a cabo pela burguesia latino-americana, que buscava, antes, liquidar a luta de classes por meio da intervenção aberta das Forças Armadas, do que conquistar uma força política própria superior àquela do movimento revolucionário, como foi o caso do fascismo (Marini et al., 1978).

Um último ponto que cumpre ressaltar a

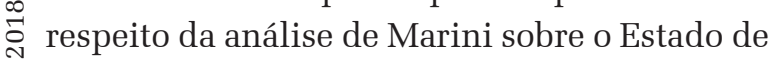
Фं contrainsurgência está relacionado aos impactos que as transformações vinculadas tanto às i in tratégia estadunidense, exercem sobre tal Es$\underset{+}{+}$ tado a partir da metade da década de 1970. A ¿ revisão da política de contrainsurgência estaके dunidense, frente à crise econômica vivida por $\overrightarrow{~ a q u e l e ~ p a i ́ s ~ e ~ a o s ~ a v a n c ̧ o s ~ d a s ~ f o r c ̧ a s ~ r e v o l u c i o-~}$ nárias em diversas partes do mundo, ganhou concretude, sobretudo, a partir do governo de Jimmy Carter, e significou, para a América Latina, a busca por uma nova política, através tanto da eliminação de pontos de fricção, como no caso do canal do Panamá, quanto de um processo de institucionalização política, na direção de uma democracia "viável", ou "democracia restringida” (Marini et al., 1978). No que tange às mudanças nas condições da luta de classes na região, Marini se refere às transformações que têm lugar em alguns países, nos quais o processo de diversificação da burguesia monopolista se encontrava mais avançado, como era o caso do Brasil. Segundo o autor, tal diversificação implica mudanças no bloco no poder, na medida em que o centro das contradições interburguesas se desloca do conflito entre a burguesia industrial e a burguesia agrária e entre as camadas inferiores da burguesia e o setor monopolista, para as divisões no seio do grande capital, ou seja, entre a própria burguesia monopolista. Em sua análise,

[...] no es posible ya, en estas circunstancias, enmascarar las luchas interburguesas tras justificaciones de corte nacionalista ni tampoco pretender encauzarlas hacia fórmulas del tipo frente antifascista, ya que ellas dividen por igual a los sectores burgueses nacionales y extranjeros que operan en el país y enfrentan a fracciones del gran capital (Marini et al., 1978, grifo do autor).

Sob essas circunstancias, de agudização das contradições interburguesas, Marini chama atenção para um movimento de transformação no Estado de contrainsurgência, por meio do qual a centralização do poder político, concentrada na elite tecnocrático-militar, tenderia a se flexibilizar, restabelecendo o lugar do parlamento como esfera de discussão e a ação dos partidos e da imprensa, de maneira que as disputas entre as frações burguesas pudessem gozar de um espaço mais amplo para sua luta política (Marini et al., 1978). Embora tal mudança não representasse uma ruptura do traço essencial do Estado de contrainsurgência, qual seja, "[...] la institucionalización de la participación directa del gran capital em la gestión económica y la subordinación de los poderes del Estado a las Fuerzas Armadas, a través de los órganos estatales que se han creado, en particular el Consejo de Seguridad Nacional" (Marini et al., 1978), Marini indica 
como possibilidade um reposicionamento das Forças Armadas nesse Estado, assumindo, a partir daquele momento, uma posição de quarto poder, controlando os demais poderes, o que corresponderia, concretamente, à preservação de seu poder político. Para o autor, tratar-se-ia de um Estado de quarto poder, como descreve no trecho a seguir:

Cualquiera que sea la fórmula adoptada - y lo más probable es que ella presente variantes en los diversos países del continente-, se marcha, sin embargo, hacia un Estado de cuatro poderes, o más precisamente, al Estado del cuarto poder, en el cual las Fuerzas Armadas ejercerán un papel de vigilancia, control y dirección sobre el conjunto del aparato estatal. Esta característica estructural y de funcionamiento del Estado no será, desde luego, sino el resultado del avasallamiento del aparato estatal por las Fuerzas Armadas (más allá de las estructuras propias de la democracia parlamentaria que éste ostente) y del ordenamiento legal de origen militar impuesto a la vida política, en particular las leyes de seguridad nacional (Marini et al., 1978, grifo do autor).

Tal conceito, ainda que tenha sido retomado em escritos posteriores de Marini, foi objeto de menor elaboração e sistematização pelo autor do que o de Estado de contrainsurgência. Cumpre ressaltar que este representava antes uma projeção acerca da forma que os Estados latino-americanos poderiam assumir em um contexto de transição para a redemocratização, do que uma análise propriamente de situações concretas.

\section{CONCLUSÃO}

Frente ao contexto recente de golpes de Estado na América Latina e no Caribe - Haiti, Honduras, Paraguai, Brasil -, cumpre avançar na compreensão das mudanças que tiveram lugar nos aparelhos de Estado, e, de maneira ainda mais importante, no poder de Estado. As reconfigurações no bloco no poder, o recrudescimento da violência de Estado sobre as classes populares e as restrições à já limitada democracia representativa liberal imputam transformações à forma de Estado dependente, transformações essas que devem ser entendidas no bojo das particularidades que engendram o capitalismo dependente latino-americano. Nesse sentido, Ruy Mauro Marini, amparado pelo debate marxista clássico sobre o Estado, e em interlocução com as elaborações de Gramsci, Althusser e Poulantzas, avança em relação à análise do Estado dependente na América Latina, contribuindo para pensar suas especificidades.

Consideramos que o autor aporta elementos relevantes para a análise dessa problemática, tais como sua periodização dos Estados latino-americanos, suas considerações em torno da autonomia relativa do Estado nas economias dependentes e da superexploração do trabalho como um elemento estruturante de tais Estados, assim como os conceitos de Estado de contrainsurgência e de subimperialismo, os quais podem, em nossa perspectiva, iluminar estudos a respeito das formas assumidas pelos Estados latino-americanos contemporâneos, e, mais ainda, indicar caminhos e possibilidades para a luta política concreta na região.

Recebido para publicação em 07 de março de 2018 Aceito em 13 de maio de 2018

\section{REFERÊNCIAS}

ALTHUSSER, L. Ideologia e aparelhos ideológicos do Estado. 3. ed. [1970]. Lisboa: Presença, 1980.

AMARAL, M. S.; CARCANHOLO, M. Acumulação capitalista e exército industrial de reserva: conteúdo da superexploração do trabalho nas economias dependentes. Revista de Economia, v. 34, p. 163-181, 2008. Número especial.

A superexploração do trabalho em economias periféricas dependentes. Revista Katál, Florianópolis, v. 12, n. 2, p. 216-225, jul./dez. 2009.

BALIBAR, E. Elementos para una teoría del tránsito. In: ALTHUSSER, L.; BALIBAR, E. Para leer el Capital. 11. ed. [1965]. Buenos Aires: SigloVeintiuno, 1969.

BICHIR, M. M. A questão do Estado na Teoria marxista da dependência. 2017. Tese (Doutorado) - Universidade Estadual de Campinas, Campinas, 2017.

BUENO, F. M.; SEABRA, R. L. El protagonismo brasileño en el siglo XXI: subimperialismo o semiperiferia? REBELA: Revista brasileira de estudos latino-americanos, v. 2, p. 7586, 2012. 
CARCANHOLO, M. (Im)precisiones acerca de la categoría superexplotación de la fuerza de trabajo. Razón y revolución, n. 25, p. 91-124, 2013.

CARCANHOLO, M.; CORRÊA, H. F. Uma teoria da superexploração da forca de trabalho em Marx? Um Marx que nem mesmo ele tinha percebido. Revista da sociedade brasileira de Economia política, n. 44, p. 10-30, jun./set. 2016.

ENGELS, F. A origem da família, da propriedade privada e do Estado. [1884]. Rio de Janeiro: Civilização Brasileira, 1977.

FONTES, V. O Brasil e o capital-imperialismo. Rio de Janeiro: UFRJ, 2010.

LUCE, M. A teoria do subimperialismo em Ruy Mauro Marini: contradições do capitalismo dependente e a questão do padrão de reprodução do capital. A história de uma categoria. 2011. 225 f. Tese (Doutorado) Universidade Federal do Rio Grande do Sul, Porto Alegre, 2011.

. A superexploração da força de trabalho no Brasil. $\overline{R e v i s t a}$ sociedade brasileira de Economia política, São Paulo, n. 32, p. 119-141, jun. 2012.

. Brasil: nova classe média ou novas formas de superexploração da classe trabalhadora? Trabalho, educação e saúde, Rio de Janeiro, v. 11, n. 1, p. 169-190, jan./abr., 2013a.

. O subimperialismo, etapa superior do capitalismo dependente. Crítica marxista, São Paulo, v. 36, p. 129-141, 2013b.

MARINI, R. M. Resenha: dialéctica del desarrollo. Foro internacional, v. 6, n. 1, sept. 1965. Disponível em: < http:// www.marini-escritos.unam.mx/pdf/326_dialectica_del_ desarrollo.pdf $\geq$. Acesso em: 9 nov. 2016.

. Reforma y revolución: una crítica a Lelio Basso. In: MARINI, R. et al. Acerca de la transición al socialismo. Buenos Aires: Ediciones periferia, 1974. Disponível em: <http://www.marini-escritos.unam.mx/051_reforma_ revolucion.html>. Acesso em: $1^{\circ}$ maio 2017.

Fricciones entre el imperialismo y la Junta: la izquierda debe avanzar. Correo de la Resistencia, MIR, n. 14, nov./dic. 1976a. Disponível em: <http://www.mariniescritos.unam.mx/305 imperialismo junta.html >. Acesso em: $1^{\circ}$ maio 2017.

El reformismo y la contrarrevolución: estudios $\stackrel{\infty}{\circ}$ sobre Chile. México, D.F.: Era, 1976b.

. Prólogo. In: BAMBIRRA, V. La revolución cubana: ญ๋ una reinterpretación. [1973]. México, D.F.: Nuestro Tiempo, 1976c.

Estado y crisis en Brasil. Cuadernos políticos, in México, n. 13, p. 76-84, jul./sept. 1977b. Disponível em: <http://www.marini-escritos.unam.mx/054_estado_ 2. crisis brasil.html>. Acesso em: $1^{\circ}$ maio 2017.

- La acumulación capitalista mundial y el A. subimperialismo. Cuadernos políticos, México, n. 12, abr./ - jun. 1977c. Disponível em: <http://www.marini-escritos. $\because$ unam.mx/052 acumulacion subimperialismo.html $>$. Acesso em: $1^{\circ}$ maio 2017

. La universidad brasileña. Revista de educación superior, México, v. 6, n. 22, abr./jun. 1977d. Disponível em <http://www.marini-escritos.unam.mx/053 universidad If brasil.html>. Acesso em: Acesso em: $1^{\circ}$ maio 2017.

Reedición de "El Principito": las dictaduras hacen girar el sol. El universal, enero 1978. Disponível em: <http://www.marini-escritos.unam.mx/188_dictaduras. html>. Acesso em: $1^{\circ}$ maio 2017.
.Alianzas y compromisos en la democracia socialista. In: CRISIS y alternativas revolucionarias en América. Montevideo: Editorial Compañero, 1987. Disponível em: $<$ http://www.marini-escritos.unam.mx/286 alianzas compromisos. html >. Acesso em: $1^{\circ}$ maio 2017̄. Ponenciā presentada en el encuentro continental celebrado en Managua (12-15 de julio de 1987), en homenaje al Che Guevara, en ocasión del XX Aniversario de su asesinato

El concepto de trabajoproductivo. Archivo de Ruy Mauro, 1993. Disponível em: <http://www.mariniescritos.unam.mx/078_trabajo_productivo.html >. Acesso em: $1^{\circ}$ maio 2017.

Análise da conjuntura política brasileira préanistia. In: TRASPADINI, R.; STEDILE, J. P. (Org.). Ruy Mauro Marini, vida e obra. São Paulo: Expressão Popular, 2005. Entrevista concedida a João Pedro Stédile, em julho de 1978 para o jornal Em Tempo, México.

Dialéctica de la dependencia. In: MARINI, R. M. América Latina, dependencia y globalización. [1972]. Buenos Aires: CLACSO-Prometeu, 2007.

MARINI, R. et al. El Estado en América Latina (mesa redonda). Revista mexicana de Ciencias políticas y sociales, n. 82, p. 9-47, oct./dic.1975.

La cuestión del fascismo en América Latina. Cuadernos políticos, n. 18, p. 13-34, oct./dic. 1978. Disponível em: <http://www.marini-escritos.unam. $\mathrm{mx} / 282$ fascismo america latina.html $>$. Acesso em: $1^{\mathrm{o}}$ maio $20 \overline{17}$.

MARTINS, C. E. Algumas reflexões em torno do conceito de superexploração do trabalho. Revista da sociedade brasileira de Economia política, v. 48, p. 28-43, set./dez. 2017.

OSORIO, J. El Estado en el centro de la mundialización. México, D.F.: Fondo de cultura económica, 2004.

Explotación redoblada y actualidad de la revolución: refundación societal, rearticulación popular y nuevo autoritarismo. México, D.F.: Itaca, 2009.

Fundamentos de la superexplotación. Razón y revolución, n. 25, p. 9-34, primer semestre 2013.

OVALLE, I. L.; NIELL, M. C. Marini y la cuestión del Estado. Cadernos cemarx, n. 9, p. 49-67, 2016.

POUlANTZAS, N. Fascismo e ditadura. [1970]. Porto: Portucalense, 1972. 2 v.

Poder político e classes sociais. [1968]. São Paulo: Martins Fontes, 1977.

SOTELO, A. La reestructuración del mundo del trabajo: superexplotación y nuevos paradigmas de la organización del trabajo. Morelia: Ítaca, 2003.

Los rumbos del trabajo: superexplotación y precariedad social en el siglo XXI. México D.F.: Miguel Ángel Porrúa, 2012. 


\section{CONTRIBUTIONS OF RUY MAURO MARINI TO THE DEBATE ON THE STATE IN DEPENDENT COUNTRIES}

\author{
Maíra Machado Bichir
}

In this article, we look at a theme of special relevance to the current Latin American political context, the State. Revisiting Ruy Mauro Marini's writings, one of the main references to the Marxist Theory of Dependence, we pretend to highlight its formulations on the Latin American States, especially on their dependent nature, which, we argue, is a subject loosely studied by the recent recoveries of his work. So, this article began with important considerations about Marini's conception of the State, emphasizing its affiliation to the Marxist theoretical tradition. Further, the study focus on the particularities of the Latin American dependent capitalist State, with special attention on two themes that represent, in our view, two important contributions of Marini to the analysis of the Latin American States, which are: his formulations on sub-imperialism and the State of counter-insurgency.

KEYwORDS: State. Dependency. Latin America. Politics. Marxist theory of dependency.

\section{CONTRIBUTIONS DE RUY MAURO MARINI AU DEBAT SUR L'ÉTAT DANS LES PAYS DEPENDANTS}

\author{
Maíra Machado Bichir
}

Dans cet article, nous examinons un thème particulièrement pertinent pour le contexte politique latino-américain actuel, l'État. Pour revenir sur les écrits de Ruy Mauro Marini, l'une des principales références de la Théorie Marxiste de la Dépendance, nous appelons l'attention sur ses formulations autour des États latino-américains, en particulier en ce qui concerne le caractère dépendant de ces États, thème encore peu exploité dans les études récentes de récupération de son travail. En ce sens, nous avons commencé notre chemin à tisser quelques considérations sur la conception de l'État de Marini, surlignant son appartenance à la tradition théorique marxiste, passant ensuite à ses élaborations sur les particularités de l'État capitaliste dépendant de l'Amérique latine spécifiquement, en se concentrant principalement sur deux thèmes qui représentent, sous notre perspective, deux contributions importantes de Marini à l'analyse des États latinoaméricains, ses formulations autour du sousimpérialisme et de l'État de la contre-insurrection.

Mots-CLÉs: État. Dépendance. Amérique latine. Politique. Théorie marxiste de la dependance.

Maíra Machado Bichir - Doutora em Ciência Política. Professora Adjunta do curso de Ciência Política e Sociologia - Sociedade, Estado e Política na América Latina, da Universidade Federal da Integração Latino-americana (UNILA). Integra o grupo de pesquisa Neoliberalismo e Relações de Classe no Brasil, vinculado ao Centro de Estudos Marxistas (CEMARX), na UNICAMP, o Grupo de Estudos de Teoria da Dependência (GETD), vinculado à UNILA e o Grupo de Estudos e Pesquisa para Alternativas em Relações Internacionais (GARI), vinculado à UNESP - Franca. Seu campo de pesquisa abrange estudos sobre pensamento político e social latino-americano, Estado, poder e dependência na América Latina. Suas mais recentes publicações são: Dossiê A atualidade do pensamento de Ruy Mauro Marini. Cadernos Cemarx, v. 9, p. 9-11, 2017; Resenha: O Estado no centro da mundialização - A sociedade civil e o tema do poder. Critica Marxista (São Paulo), v. 42, p. 191-193, 2016. 
